\title{
Removal and recovery of mercury from chlor-alkali petrochemical wastes using $\gamma-\mathrm{Fe}_{2} \mathrm{O}_{3}$ nanoparticles
}

\author{
Zahra Ramezani $^{1,2} \cdot$ Neda Pourmand ${ }^{2,3} \cdot$ Abdolazim Behfar $^{1,2} \cdot$ Ali Momeni ${ }^{2,4}$
}

Received: 29 April 2015/ Accepted: 2 August 2016/Published online: 23 August 2016

(c) The Author(s) 2016. This article is published with open access at Springerlink.com

\begin{abstract}
One of the main sources of mercury pollutions in Bandar Imam petrochemical company is its chlor-alkali unit. The unit uses mercury to convert sodium chloride $(\mathrm{NaCl})$ to chlorine and sodium hydroxide. In this study, removal and recovery of mercury from wastewater of the chlor-alkali unit before its conversion to cake using $\gamma-\mathrm{Fe}_{2} \mathrm{O}_{3}$ nanoparticles were reported. It was shown that the magnetic nanoparticles can adsorb and remove mercury from the chlor-alkali unit wastes and the resulting sorbents effectively separated from the solution by a $1.4 \mathrm{~T}$ magnet. Different parameters, which could affect the adsorption process, such as the amount of nanoparticles, $\mathrm{pH}$ and volume of buffer, and contact time were optimized. Under the optimized conditions, $94.59 \%$ of mercury was removed using bare nan $\gamma-\mathrm{Fe}_{2} \mathrm{O}_{3}$ with RSD of $1.7 \%$ $(n=5)$. Adsorbed $\mathrm{Hg}$ (II) was successfully desorbed using $1 \mathrm{M} \mathrm{HCl}$, then the resulting solution's mercury content was reduced to elemental mercury. The elemental mercury was finally collected in a hollow glass gas chromatographic column half filled with distilled water, providing a green chemistry for reuse of mercury. The method of mercury
\end{abstract}

Zahra Ramezani

zramezani@ajums.ac.ir

1 Nanotechnology Research Center, Faculty of Pharmacy, Ahvaz Jundishapur University of Medical Sciences, Ahvaz, IR, Iran

2 Medicinal Chemistry Department, Faculty of Pharmacy, Ahvaz Jundishapur University of Medical Sciences, Ahvaz, IR, Iran

3 Department of Chemistry, Faculty of Science, Ahvaz Branch of Azad University Science and Research Center, Ahvaz, Iran

4 Mahshahr Petrochemical Companies, Mahshahr, Iran determination was cold vapor atomic adsorption spectrometry throughout this study.

Keywords Petrochemical waste Chlor-alkali unit . $\gamma-\mathrm{Fe}_{2} \mathrm{O}_{3}$ nanoparticles $\cdot$ Mercury, remediation

\section{Introduction}

Mercury is one of the most toxic heavy metals in wastewaters released from industrial activities, such as the pharmaceutical, agricultural and petrochemical industries into the environment and creating problems for humans as well as aquatic organisms due to its toxic and bio-accumulative properties [1]. Mercury pollution constitutes serious worldwide environmental problem [2-5]. Globally, it has been estimated that 5500 tons of mercury are discharged into the atmosphere annually. Reactive mercury (II) salts are toxic form of mercury, which are often converted by bacteria into the most toxic form, methyl mercury, which create a health risk to humans and wildlife [6]. Generally, discharge of mercury from industrial wastewater is directed to the natural water bodies, such as rivers, lakes and seas. The European Union considers mercury as a priority and hazardous pollutant and defines a maximum permissible concentration of total mercury as low as $1 \mu \mathrm{g} \mathrm{L}^{-1}$ for drinking water and $5 \mu \mathrm{g} \mathrm{L}^{-1}$ for wastewater discharge [7]. Volcanic eruptions, naturally caused forest fires, and biogenic emissions are natural inputs of mercury to the environment [8]. In addition, unnatural ways for mercury pollution are wastewater of chlor-alkali plants, vinyl chloride plants, plastics industry, electrical equipment, batteries, and paints $[9,10]$. Chlor-alkali plants (CAP) are one important source of $\mathrm{Hg}$ emissions, which use metallic $\mathrm{Hg}$ to convert $\mathrm{NaCl}$ to chlorine and sodium 
hydroxide $[11,12]$. Several studies have exposed that most $\mathrm{Hg}$ emitted from chlor-alkali plants is dispersed over long distances [13, 14]. Nevertheless, it has been reported by EPA that soils surrounding chlor-alkali plants show $\mathrm{Hg}$ concentrations up to 75 times the background. It should be mentioned that water contents of the chlor-alkali waste are evaporated and a solid waste that is called "cake" are released into the environment. Therefore, the removal of mercury from chlor-alkali plants wastes is necessary before the effluent is discharged into the environment $[15,16]$. As a consequence, the development of effective techniques for the removal of mercury from wastewater and related sources is very important for the remediation of mercury pollution. Air emission and wastewater treatment standards are gradually becoming tighter all over the world. Research and development of pollution control technology has been focusing on improving the removal efficiency of all contaminates, minimizing water and energy consumptions [17]. A number of technologies have been developed over the years to remove toxic metal ions from water $[18,19]$. Conventional methods for the removal of heavy metals include ion exchange, chemical precipitation, pre concentration, reverse osmosis, evaporation, membrane filtration, adsorption and bio sorption [20-25]. Therefore, abatement of mercury from industrial wastewater to attain the stipulated limit as prescribed by EPA is mandatory.

In recent years considerable attention has been given to remove mercury by adsorption process on various adsorbent, a number of pre concentration techniques have been used for trace metal remediation: These include coagulation, precipitation/coprecipitation and solid phase adsorption [26-29].

Nowadays, adsorption is a well-recognized technique and has been applied for cleaning up of numerous different classes of compounds in a variety of matrices by virtue of its high absorptivity, recovery, and rapid phase separation [30-33]. Separation by magnet is a relatively new solid phase adsorption method which according to the characteristics of the target systems can be used in two different ways; firstly using of external magnetic field as a separation tool of magnetic target, secondly using of external magnetic field to separate nonmagnetic target for instance organic and inorganic compounds. Separation of nonmagnetic target such as organic molecule is through formation of a complex with magnetic particles which shall then be separated by an external magnetic field [34-36].

The aim of this study is to develop a new environmentally friendly and less expensive adsorbent suitable for removal of mercury from industrial wastewater and to check whether the adsorbed metal can be recovered from the spent adsorbent for reuse. In this work, $\gamma-\mathrm{Fe}_{2} \mathrm{O}_{3}$ Nanoparticles (MIONs) was used for the removal and recovery of mercury from chlor-alkali plant wastewater.
The major objective of this work is to investigate the potential of $\gamma-\mathrm{Fe}_{2} \mathrm{O}_{3}$ as adsorbent for mercury removal from the waste. To do so, the effect of parameters such as amount of $\gamma-\mathrm{Fe}_{2} \mathrm{O}_{3}$ nanoparticles (MIONs), $\mathrm{pH}$ and volume of buffer solution, and stirring time in the removal process is optimized. Recovery of mercury (II) from spent MIONs was studied to check the reusability of the MIONs and mercury. Different adsorption isotherms were also checked and the best model was introduced.

\section{Experimental}

\section{Instrumentation}

Cold vapor atomic absorption spectrometry (CV-AAS) determination of mercury in field samples was performed by a flame AAS instrument (CTA-3000, Anal. tech England) equipped with a Mercury Vaporizer Unit MVU-1A (Shimadzue) and hollow tube with quartz windows as CV_AAS cell, placed in the light path of the spectrometer. A pH meter (632 Metrohm, Herisau, Switzerland) was used to adjust $\mathrm{pH}$ of the solutions. A $1.4 \mathrm{~T}$ super magnet $(10 \times 5 \times 2 \mathrm{~cm})$, a mechanical stirrer (E649 Metrohm, Herisau, Switzerland), and ultrasonic bath (Transistor/ultrasonic T-14, USA) were used throughout the study.

\section{Reagents and standard solutions}

All chemicals and reagents were of analytical grade unless otherwise stated. Nitric acid $\left(\mathrm{HNO}_{3}, 65 \%\right)$, sulfuric acid $\left(\mathrm{H}_{2} \mathrm{SO}_{4}, 98 \%\right)$, hydrochloric acid $(\mathrm{HCl}, 37 \%)$, Potassium permanganate $\left(\mathrm{KMnO}_{4}\right)$, Hydroxylamine Hydrochloride $\left(\mathrm{H}_{4} \mathrm{ClNO}\right)$, Tin (II) chloride $\left(\mathrm{SnCl}_{2} \cdot 2 \mathrm{H}_{2} \mathrm{O}\right)$ were purchased from Merck (Darmstadt, Germany). Nano iron oxide $(\gamma$ $\mathrm{Fe}_{2} \mathrm{O}_{3}$ ) with size of $15-25 \mathrm{~nm}$, SSA: $50 \mathrm{~m}^{2} \mathrm{~g}^{-1}$, and purity $95 \%$ was purchased from Tehran petrochemical industry (Tehran, Iran). Figure 1 shows the XRD of $\gamma-\mathrm{Fe}_{2} \mathrm{O}_{3}$ Nanoparticles that was sent by the manufacturer. The peaks

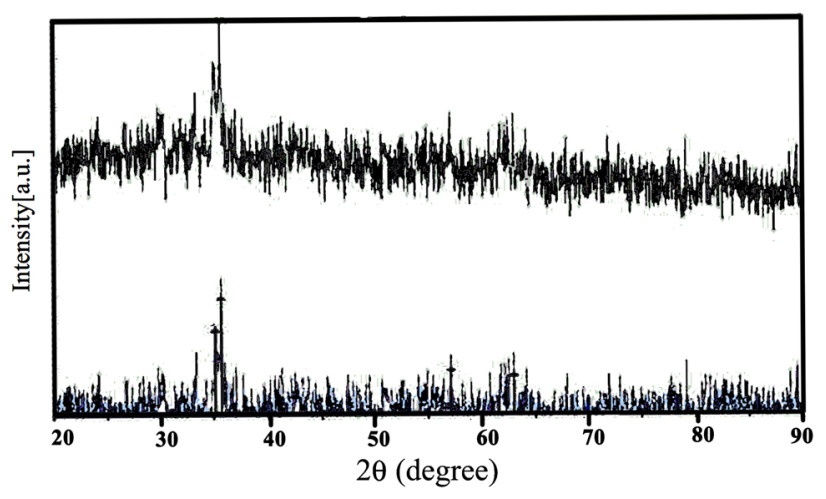

Fig. 1 XRD of $\gamma-\mathrm{Fe}_{2} \mathrm{O}_{3}$ magnetic nanoparticles 
observed at $2 \Theta$ ranges of $30-40,60-65$ and $70-80$ (weak) are indicative of $\gamma-\mathrm{Fe}_{2} \mathrm{O}_{3}$ nanoparticles.

\section{Sample collection and treatments}

About $10 \mathrm{~L}$ composite samples of chlor-alkali petrochemical wastes from Mahshahr petrochemical company (Mahshahr, Iran) were transferred to our laboratory. Its total mercury contents were determined before starting any experiments. All experiments including optimizations were performed directly on these wastes. The mean mercury contents of wastes were determined by CV-AAS and was $9.36 \mathrm{mg} \mathrm{mL}^{-1}$.

\section{Adsorption procedure}

Adsorption of mercury on $\gamma-\mathrm{Fe}_{2} \mathrm{O}_{3}$ Nanoparticles (MIONs) were investigated by diluting appropriate amount of petrochemical wastewater to $50 \mathrm{~mL}$ by nitric acid $(1 \mathrm{M})$. The resulting solution was transferred to a beaker, the $\mathrm{pH}$ was adjusted and appropriate amount of MIONs was added. The mixture was stirred using an ultrasonic bath for about $20 \mathrm{~min}$. Mercury adsorbed MIONs was then collected by placing the beaker on the $1.4 \mathrm{~T}$ magnet and allowing the upper solution to become colorless, and then decanted. Removal percentage of mercury was determined by concentrations of mercury in the waste solution before and after the nanoparticle contact with aid of cold vapor atomic absorption spectrometric technique (CV-AAS) at mercury line $(253.7 \mathrm{~nm})$. Nitric acid $(0.1 \mathrm{M})$ and $0.1 \mathrm{M}$ $\mathrm{NaOH}$ solutions was used for $\mathrm{pH}$ adjustment.

\section{Results and discussion}

All the experiments were performed on the diluted petrochemical waste as indicated in the previous section. The effects of different parameters on mercury extraction were studied to reach higher removal efficiency. The results of each are discussed separately.

\section{Effect of the amount of $\gamma-\mathrm{Fe}_{2} \mathrm{O}_{3}$ nanoparticles (MIONs)}

The amount of $\gamma-\mathrm{Fe}_{2} \mathrm{O}_{3}$ nanoparticles (MIONs) used in this work was varied from 5 to $50 \mathrm{mg}$. The results are graphically shown in Fig. 2. The results indicated that the higher removal was observed at $20 \mathrm{mg}$ of MIONs. Slight decrease (about 1-3\%) in removal efficiency with increase in sorbent amount may be due to variation in surface charges of the nanoparticles in the presence of the sample matrices. This was confirmed by the excess MIONs remained

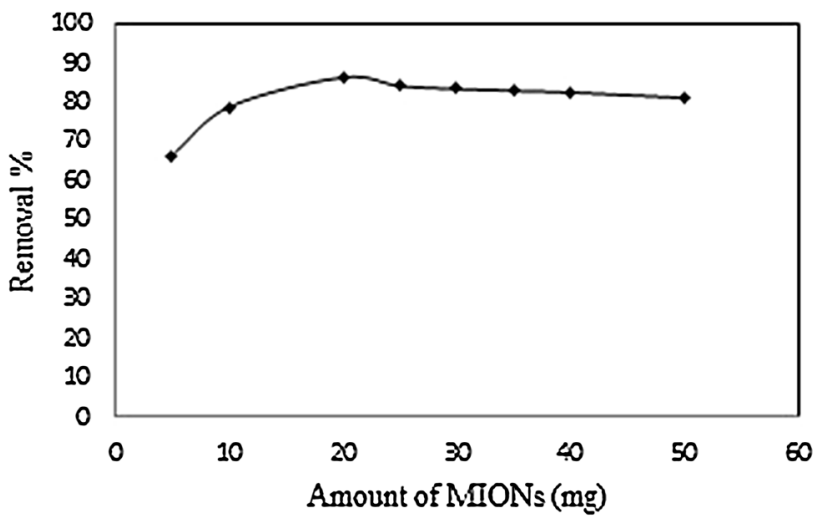

Fig. 2 Effect of different amounts of $\gamma-\mathrm{Fe}_{2} \mathrm{O}_{3}$ nanoparticles (MIONs) on the mercury separation (stirring time: $30 \mathrm{~min}$, diluted petrochemical waste). The presented data were average of three replicated analysis

floating on the solution when applying a magnetic field. So the $20 \mathrm{mg}$ was chosen as the optimum value.

\section{Effect of pH}

The effect of $\mathrm{pH}$ was examined by varying the $\mathrm{pH}$ of the test solution in the range of $2-10$. The $\mathrm{pH}$ of $1 \mathrm{~mL}$ of wastewater solution $\left(9.36 \mathrm{mg} \mathrm{L}^{-1}\right)$ was adjusted to the desired value using $\mathrm{HNO}_{3}$ and/or $\mathrm{NaOH}$ solution $(0.1 \mathrm{M})$, diluted to $50 \mathrm{~mJ}$ and $20 \mathrm{mg}$ of MIONs was added as the adsorbing agent. As the Fig. 3 indicates the removal efficiency of the $\gamma-\mathrm{Fe}_{2} \mathrm{O}_{3}$ nanoparticles (MIONs) are approximately the same (more than $86.15 \%$ ) in the $\mathrm{pH}$ ranges of 3-8. At lower $\mathrm{pH}$, the solution became dark brown due to dissolution of iron oxide nanoparticles. On the other hand in solutions with high $\mathrm{pH}$ values (above $\mathrm{pH} 8$ ), the particles were converted to a colloidal form that did not settle by the

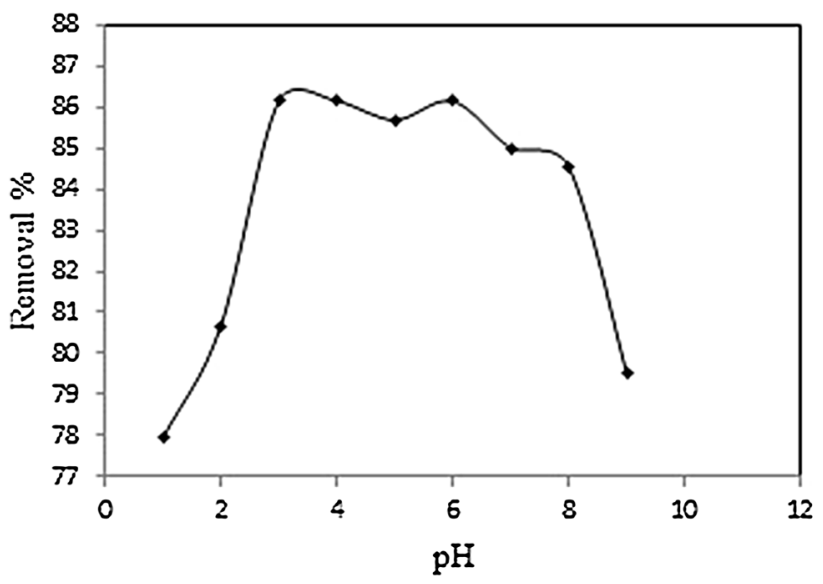

Fig. 3 Effect of $\mathrm{pH}$ on the mercury adsorption (conditions: $0.02 \mathrm{~g}$ of MIONs; stirring time: $30 \mathrm{~min}$, diluted petrochemical waste). The presented data were average of three replicated analysis 
applied magnetic field (Fig. 3), indicating strong adsorption of hydroxide ions. Thus, $\mathrm{pH}$ is not a critical limiting factor on the proposed removal process and $\mathrm{pH}$ in the range of 3-8 can be selected. Therefore, in further experiments, the $\mathrm{pH}$ of the solutions was adjusted to 5 . It is to be mentioned that the waste had $\mathrm{pH}$ over 9.

\section{Effect of buffer volume}

The effect of buffer volume on the mercury removal of the petrochemical waste $\left(0.1872 \mu \mathrm{g} \mathrm{mL}^{-1}\right)$ by the present magnetic adsorbent (MIONs) was investigated. The results indicated that a slight decrease in removal efficiency was observed at different buffer volume (pH 5 and $20 \mathrm{mg}$ of MIONs). So, minimum amount of the acid is required to adjust $\mathrm{pH}$ of the waste to the desired value. This may be because of the wide obtained $\mathrm{pH}$ optimization range.

\section{Effect of stirring time}

The effect of stirring (contact) time on the mercury removal of the chlor-alkali waste solution after addition of MIONs is shown in Fig. 4. As can be seen from the figure, the removal increases with increase in the stirring time up to $20 \mathrm{~min}$, afterward a slight decrease was observed (about 9 percent decrease on 20 min increase in contact time). Since no modification is made to selectively adsorb the mercury, the small decrease was due to adsorption desorption equilibrium of the other competitive ions in the waste. Therefore, at bare $\gamma-\mathrm{Fe}_{2} \mathrm{O}_{3}$ nanoparticles adsorption rate was indicated by the removal of more than $94.59 \%$ of mercury in the $20 \mathrm{~min}$ at optimum values of other factors indicated in Fig. 4 captions. So the 20 min contact time is the best choice.

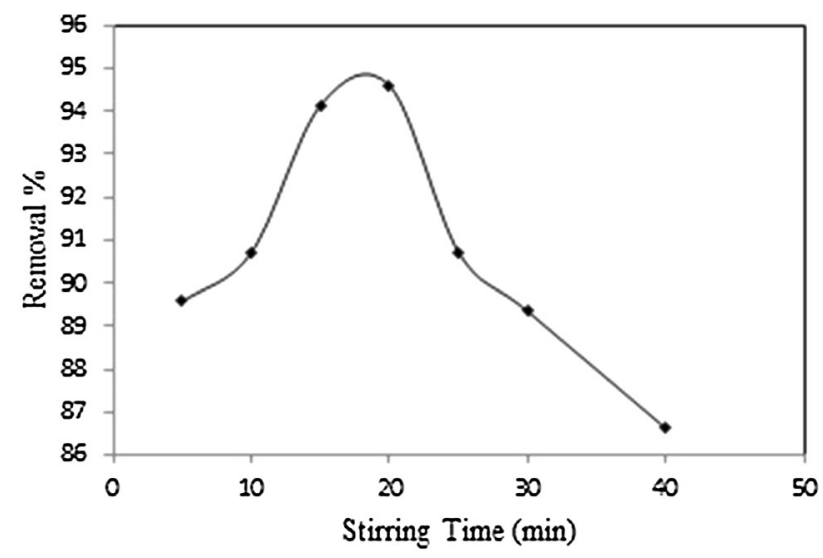

Fig. 4 Effect of stirring time on the mercury adsorption (conditions: $0.02 \mathrm{~g}$ of MIONs; $\mathrm{pH} 5$, buffer volume $=4 \mathrm{~mL}$ ). The presented data were average of three replicated analysis

\section{Effect of the petrochemical waste volume}

Different amounts of the petrochemical waste having mercury concentration in the range of $0.1872-9.36 \mu \mathrm{g} \mathrm{mL}^{-1}$ at optimum conditions ( $\mathrm{pH} 5$, $20 \mathrm{mg}$ sorbent) were mixed and stirred by sonication for 20 min. About $91 \%$ mercury removal was observed for mercury concentrations up to $1.872 \mu \mathrm{g} \mathrm{mL}^{-1}$. At higher mercury contents, twofold increase in mercury contents results in $25 \%$ decrease in mercury uptake by the sorbent. This may happen because of maximum sorbent capacity of the mercury is reached (Fig. 5). It indicated that the waste dilution should be controlled to keep the mercury level at about $0.4 \mathrm{ppm}$ in treatment vessels, otherwise, the sorbents amount must be increased. By conducting different experiments at optimum conditions on the diluted waste, it was concluded that mercury in the diluted wastes can be reduced below the permitted level reported by the European Union $\left(5 \mathrm{ng} \mathrm{mL}^{-1}\right)$ for waste water.

\section{Maximum adsorption capacity}

Maximum adsorption capacity of the sorbent was studied by contacting $10 \mathrm{~mL}$ portions of solutions containing $50 \mu \mathrm{g} \mathrm{mL}^{-1}$ standard mercury with $0.5 \mathrm{~g}$ of MIONs for predetermined time followed by determination of the effluent and retained mercury using CV-AAS. The maximum capacity was calculated as $234 \mathrm{ng} \mathrm{mg}^{-1}$. The adsorption capacity was also determined from different adsorption isotherms presented in Table 1 .

\section{Recovery}

Mercury released into the environment enters the human body through the food chain. Chronic exposure to $\mathrm{Hg}^{\circ}$

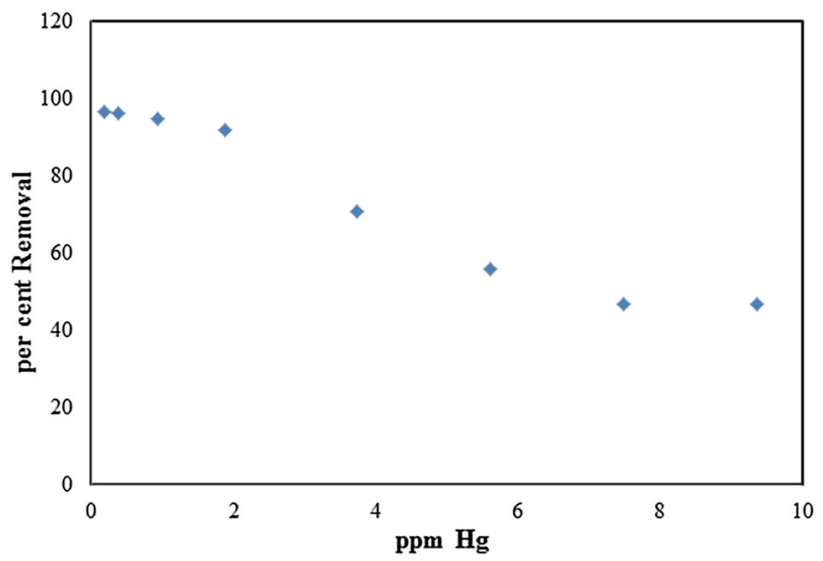

Fig. 5 Effect of the petrochemical waste concentration on the mercury adsorption (conditions: $0.02 \mathrm{~g}$ of MIONs; $\mathrm{pH} 5$, buffer volume $=4 \mathrm{~mL}$; stirring time: $20 \mathrm{~min}$ ). The presented data were average of three replicated analysis 
Table 1 Langmuir, Freundlich, Temkin and Dubinin-Radushkevich isotherm constants for the adsorption of mercury on the $\gamma$-Fe $\mathrm{O}_{3}$ nanoparticles

\begin{tabular}{|c|c|c|c|c|c|c|c|c|c|c|c|c|}
\hline \multirow{3}{*}{ Parameters } & \multicolumn{3}{|l|}{ Langmuir } & \multicolumn{3}{|c|}{ Freundlich } & \multicolumn{3}{|l|}{ Temkin } & \multicolumn{3}{|c|}{ Dubinin-Radushkevich } \\
\hline & $Q_{m}\left(\mathrm{mg} \mathrm{g}^{-1}\right)$ & $K_{L} \mathrm{~L} \mathrm{mg}^{-1}$ & $R_{L}$ & $1 / n$ & $n$ & $K_{f}\left(\mathrm{mg} \mathrm{g}^{-1}\right)$ & $A_{T} \mathrm{~L} \mathrm{~g}^{-1}$ & $b_{T}$ & $B \mathrm{~J} \mathrm{~mol}^{-1}$ & $q_{s}\left(\mathrm{mg} \mathrm{g}^{-1}\right)$ & $K_{\mathrm{ad}}\left(\mathrm{mol}^{2} / \mathrm{J}^{2}\right)$ & $\mathrm{E}\left(\mathrm{KJ} \mathrm{mol}^{-1}\right)$ \\
\hline & 0.69348 & 497.24 & 0.1773 & 1.6321 & 0.6127 & 2018.8 & $7.15 \times 10^{20}$ & 20458.9 & 0.1211 & 2.1877 & $1 \times 10^{-9}$ & 22.36 \\
\hline$R^{2}$ & 0.9927 & & & 0.9926 & & & 0.9584 & & & 0.9991 & & \\
\hline
\end{tabular}

vapors also can damage the kidneys and neurologic system. However, before release of the chlor-alkali sewage into the environment it is strongly recommended to remove mercury. Also the sorbents used for mercury remediation such as the present nanoparticles should not be released into the environment. So the recovery and reusability of the nanoparticles and the mercury seems necessary.

Hydrochloric acid is commonly used for some metal ions elution, including $\mathrm{Hg}$ (II), from adsorbents surfaces due to its common usage in industry. Recovery of the adsorbate may be a secondary objective, and the more concentrated the adsorbate is in desorption fluid the more likely the success of the process. Therefore, in this work, we added hydrochloric acid on the spotty nanoparticles for recovery of mercury and recycling of nanoparticles. Finally, the recovered mercury ions were recycled as metallic mercury.

\section{Influence of hydrochloric acid concentration}

When using strong acid it is possible that desorption could occur along with nanoparticles dissolution as a result of acid solubilization of the nanoparticle. This was checked using different concentration of $\mathrm{HCl}$ in a desorption trial. The results showed that nanoparticles were dissolved in $\mathrm{HCl}$ with concentrations higher than $1 \mathrm{M}$. The addition of $10 \mathrm{~mL}$ portions of acceding concentration of $\mathrm{HCl}(0.1,0.5$, 0.7 and $1.0 \mathrm{M}$ ) as a recovery agent, indicated an increase in mercury desorption up to $1 \mathrm{M}$. So, $1 \mathrm{M} \mathrm{HCl}$ was used as the recovery solvent.

\section{Influence of hydrochloric acid volume}

Different amounts of $1 \mathrm{M}$ hydrochloric acid were added to the spotty $\gamma-\mathrm{Fe}_{2} \mathrm{O}_{3}$ nanoparticles to desorb the mercury from the surface. Figure 6 shows that desorption efficiency increases with increase in $\mathrm{HCl}$ volume. A maximum mercury recovery of $93.92 \%$ was observed for $8 \mathrm{ml}$ of $1.0 \mathrm{M}$ $\mathrm{HCl}$ solution as the elution solvent.

\section{Recovery of elemental mercury $\left(\mathrm{Hg}^{\circ}\right)$ from spotty Hydrochloric acid}

A system presented in Fig. 7a was designed to recovered mercury from contaminated $\mathrm{HCl}$ in our laboratory. The

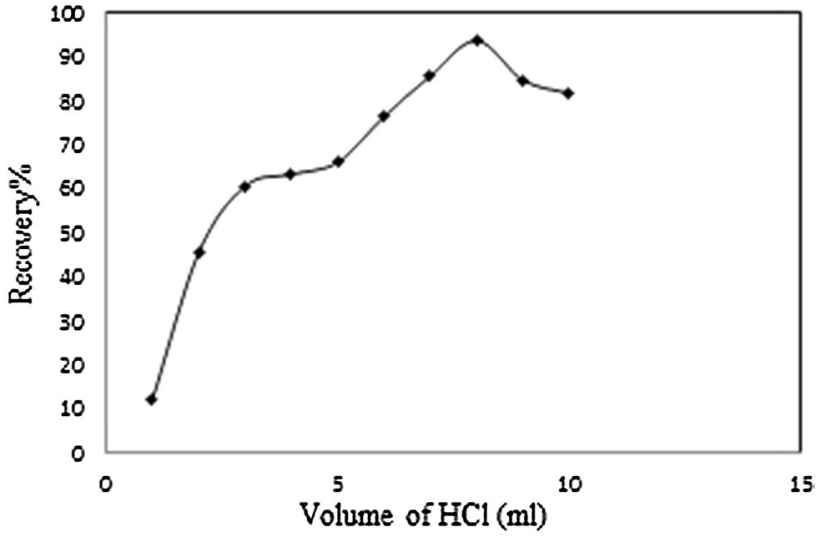

Fig. 6 Influence of hydrochloric acid volume on mercury elution from the nanoparticle surface

system is much like the cold vapor system except for mercury trapping segment. Tin (II) chloride was used to reduce $\mathrm{Hg}^{2+}$ to $\mathrm{Hg}$. The generated $\mathrm{Hg}$ was passed through the system by means of nitrogen gas. As it can be seen from the Fig. 7b, a hollow glass gas chromatography column half filled with distilled water which was completely covered by ice was placed in the mercury reduction line (Fig. 7a) to trap metallic mercury on cooling the $\mathrm{Hg}$ vapors. The elemental mercury can be reused in chloralkali plant and thus protecting the environment. To prevent release of traces of mercury into the environment, the acidic permanganate solution was placed at the end of the transfer line. The mercury recovery was about $94 \%$.

\section{Sorption isotherms}

Langmuir, Freundlich, Temkin, and Dubinin-Radushkevich isotherms models were fitted to determine the adsorption mechanism of the mercury from the petrochemical waste onto the $\gamma-\mathrm{Fe}_{2} \mathrm{O}_{3}$ nanoparticles. The equations and their linear form used for evaluation of the sorption systems are briefly described below.

Langmuir Adsorption Isotherm equation [37] is:

$q_{\mathrm{e}}=\frac{q_{\mathrm{m}} K_{\mathrm{L}} C_{\mathrm{e}}}{1+K_{\mathrm{L}} C_{\mathrm{e}}}$

and its linear form which is used to calculate the corresponding isotherm parameters is: 
Fig. 7 a schematic design for conversion of mercury contaminated $\mathrm{HCl}$ to elemental mercury, $\mathbf{b}$ released mercury that is trapped in the glass coil placed on ice

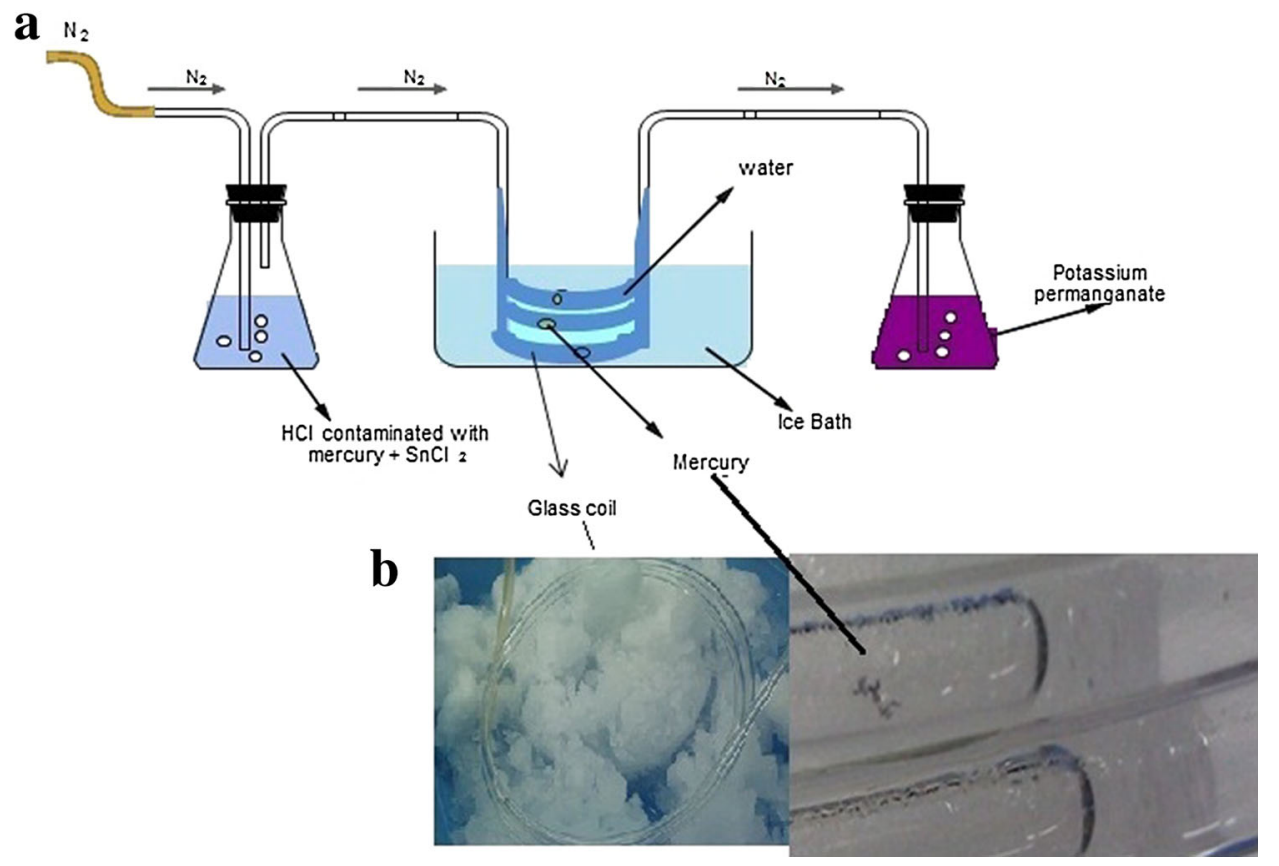

$\log q_{\mathrm{e}}=\log K_{\mathrm{f}}+\frac{1}{n} \log C_{\mathrm{e}}$

The constant $K_{\mathrm{f}}$ is an approximate indicator of adsorption capacity, while $1 / n$ determines the adsorption strength in the adsorption process [39]. The values more than 1 for $1 /$ $n$ parameter implies to the fact that a cooperative adsorption occurs [40]. In this study not only the experiments are directly performed on waste, which contains some cations and anions, but also no modification on the sorbent surfaces for selective adsorption of mercury is done. Therefore, as it is indicated in Table 1 the $1 / n$ value of 1.6321 confirms occurrence of cooperative adsorption in mercury removal from the waste using bare $\gamma-\mathrm{Fe}_{2} \mathrm{O}_{3}$ nanoparticles. [41]

The Temkin model is given by the following equation

$$
\begin{aligned}
& q_{\mathrm{e}}=\frac{\mathrm{RT}}{b_{\mathrm{T}}} \operatorname{Ln} A_{\mathrm{T}}+\frac{\mathrm{RT}}{b_{\mathrm{T}}} \operatorname{Ln} C_{\mathrm{e}} \\
& B=\frac{\mathrm{RT}}{b_{\mathrm{T}}}
\end{aligned}
$$

$A_{\mathrm{T}}=$ Temkin isotherm equilibrium binding constant $\left(\mathrm{L} \mathrm{g}^{-1}\right), b_{\mathrm{T}}=$ Temkin isotherm constant, $R=$ Universal gas constant $\left(8.314 \mathrm{~J} \mathrm{~mol}^{-1} \mathrm{~K}\right), \quad T=$ Temperature at $298 \mathrm{~K}, B=$ Constant related to heat of sorption $\left(\mathrm{J} \mathrm{mol}^{-1}\right)$.

Dubinin-Radushkevich isotherm (DRK) model and its linear form are described by the following equations

$q_{\mathrm{e}}=q_{\mathrm{s}} e^{\left(-B_{\mathrm{DR}} \varepsilon^{2}\right)}$

$\operatorname{Ln} q_{\mathrm{e}}=\operatorname{Ln} q_{\mathrm{s}}-B_{\mathrm{DR}} \varepsilon^{2}$ 
Table 2 Comparison of mercury removal methods used for industrial waste treatments

\begin{tabular}{|c|c|c|c|c|c|c|}
\hline Adsorbate & $\mathrm{pH}$ range & Capacity & Time & Con (ppm) & Adsorption \% & References \\
\hline Acetobacter xylinum cellulose & $5-8$ & $65 \mu \mathrm{g} \mathrm{g}^{-1}$ & $10 \min$ & 9.638 & 95.64 & [45] \\
\hline MBI-Clay ${ }^{\mathrm{a}}$ & $4-8$ & $250 \mathrm{mg} \mathrm{g}^{-1}$ & $8 \mathrm{~h}$ & $28-100$ & $75-99$ & [5] \\
\hline SA-activated carbon ${ }^{\mathrm{b}}$ & $4-9$ & $188.7 \mathrm{mg} \mathrm{g}^{-1}$ & $4 \mathrm{~h}$ & $50-100$ & Above 90 & [33] \\
\hline NAC-activated carbon ${ }^{\mathrm{c}}$ & $6-9$ & Below 188.7 & $4 \mathrm{~h}$ & $50-100$ & Above 60 & {$[33]$} \\
\hline Bare $\gamma-\mathrm{Fe}_{2} \mathrm{O}_{3}$ & $3-8$ & $234 \mathrm{mg} \mathrm{g}^{-1}$ & $20 \mathrm{~min}$ & $0.1-0.400$ & $83-94.5$ & Present me \\
\hline
\end{tabular}

a 2-Mercaptobenzimidazole-clay (MIB-clay)

b Sulfur activated

${ }^{c}$ Non activated

Dubinin-Radushkevich isotherm is generally applied to express the Gaussian energy distribution onto a heterogeneous surface [42].

where $q_{\mathrm{e}}=$ amount of adsorbate in the adsorbent at equilibrium $\left(\mathrm{mg} \mathrm{g}^{-1}\right), q_{\mathrm{s}}=$ theoretical isotherm saturation capacity $\left(\mathrm{mg} \mathrm{g}^{-1}\right), \quad B_{\mathrm{DR}}=$ Dubinin-Radushkevich isotherm constant $\left(\mathrm{mol}^{2} / \mathrm{J}^{2}\right)$.

The model was usually applied to distinguish the physical and chemical adsorption including ion exchange of metal ions on solid sorbents. Mean free energy of adsorption (E) can be determined by $E=$ $\frac{1}{\sqrt{2 B_{\mathrm{DR}}}}$ [43]. The $\varepsilon$ can be calculated using $\varepsilon=$ RT $\ln \left[1+\frac{1}{C_{\mathrm{e}}}\right]$ With the obtained $E=22.36 \mathrm{~kJ} \mathrm{~mol}^{-1}$ for the DRK model applied on the results (Table 1), it should be concluded that a chemisorption process has been occurred. From $R^{2}$ presented in Table 1, it can be seen that Langmuir and Freundlich isotherms have shown approximately the same correlation coefficient whereas the Temkin has the least correlation among the considered models, and DRK with the $R^{2}=0.9991$ shows the best correlation. However, the adsorption obeyed DRK model. It should be recalled that the DRK model is usually capable to describe the metal adsorption on the surface of the inorganic sorbents as it is the case in this study. It should be noticed that the presence of both mercury ion and metallic mercury is appropriate in this waste. $R^{2}$ value of the Langmuir isotherms that usually describe gas phase adsorption, and that of Freundlich both indicate these two forms of mercury in the waste.

To our knowledge, there was limited works on chloralkali mercury removal using adsorption technology. Some of them are listed in Table 2 for comparisons. As it is indicated on the table, the present sorbent is capable of removing mercury at trace levels without any surface modification with good capacity at short time.

\section{Conclusion}

In conclusion, $\gamma-\mathrm{Fe}_{2} \mathrm{O}_{3}$ nanoparticles (MIONs) are an effective sorbent for separation and pre-concentration of trace amounts of mercury from the wastewater of chloralkali unit. As it is reported by other researcher, some sorbent can be used for mercury removal without any modifications. Even chloride and oxide forms of mercury can be adsorbed on the surface of the sorbents better than mercury itself [44]. In petrochemical waste, chloride ion is present and probably the mercury chloride produced is simply adsorbed on the $\gamma-\mathrm{Fe}_{2} \mathrm{O}_{3}$ nanoparticles. The results also indicated that no modification of $\gamma-\mathrm{Fe}_{2} \mathrm{O}_{3}$ nanoparticles was required. It may be because of the self-modification by the matrix components (cooperative adsorption) as it was also concluded from $1 / n$ value obtained by the Freundlich isotherm. With concise control of the parameters affecting the sorption of the mercury removal efficiency reached $94.59 \%$ in the present waste. The greatest improvement of this method is that the desired materials are separated from the petrochemical waste by a simple and efficient process while less or even no secondary wastes are produced. Other improvement is the conversion of $\mathrm{Hg}(\mathrm{II})$ to $\mathrm{Hg}^{\circ}$ for reuse in chlor-alkali plant. However, simple, rapid, reproducible, and low cost system is introduced. It was also found that MIONs did not keep any magnetization after the removal of an external magnetic field which proved the super paramagnetic characteristic of these nanoparticles. Above all the main advantage is that the mercury content of petrochemical cake, the final form of chlor-alkali waste, released in the environment reaches below the waste permitted levels $\left(5 \mathrm{ng} \mathrm{mL}^{-1}\right)$.

Acknowledgments The authors acknowledged the financial supports of petrochemical company research and development center, Mahshahr, Iran and the nanotechnology research center of Ahvaz Jundishapur University of medical sciences who support this work under grant number $\mathrm{N} 7$. 
Open Access This article is distributed under the terms of the Creative Commons Attribution 4.0 International License (http:// creativecommons.org/licenses/by/4.0/), which permits unrestricted use, distribution, and reproduction in any medium, provided you give appropriate credit to the original author(s) and the source, provide a link to the Creative Commons license, and indicate if changes were made.

\section{References}

1. Kazi T, Jalbani N, Kazi N, Jamali MK, Arain MB, Afridi HI et al (2008) Evaluation of toxic metals in blood and urine samples of chronic renal failure patients, before and after dialysis. Ren Fail 30:737-745

2. ShokrollahiI A, Ghaedi M, Shamsipur M (2009) Highly selective transport of mercury(II) ion through a bulk liquid membrane. Quim Nova 32:153-157

3. Ghodbane I, Hamdaoui O (2008) Removal of mercury (II) from aqueous media using eucalyptus bark: kinetic and equilibrium studies. J Hazard Mater 160:301-309

4. Ghaedi M, Fathi MR, Shokrollahi A, Shajarat F (2006) Highly selective and sensitive preconcentration of mercury ion by cold vapor atomic absorption spectroscopy. Anal Lett 39:1171-1185

5. Manohar DM, Krishnan KA, Anirudhan TS (2002) Removal of mercury(II) from aqueous solutions and chlor-alkali industry wastewater using 2-mercaptobenzimidazole-clay. Water Res 36:1609-1619

6. Miretzky P, Cirelli AF (2009) $\mathrm{Hg}$ (II) removal from water by chitosan and chitosan derivatives: a review. J Hazard Mater 167:10-23

7. Natale FD, Lancia A, Molino A, Di Natale M, Karatza D, Musmarra D (2006) Capture of mercury ions by natural and industrial materials. J Hazard Mater 132:220-225

8. Morel FMM, Kraepiel AML, Amyot M (1998) The chemical cycle and bioaccumulation of mercury. Ann Rev Ecol Syst 29:543-566

9. Boening DW (2000) Ecological effects, transport, and fate of mercury: a general review. Chemosphere 40:1335-1351

10. Fitzgerald WF, Engstrom DR, Mason RP, Nater EA (1998) The case for atmospheric mercury contamination in remote areas. Environ Sci Technol 32:1-7

11. Maserati EB, Ferrara R (1991) Mercury in plants, soil and atmosphere near a chlor-alkali complex. Water Air Soil Pollut 56:15-20

12. Baldi F, Bargagli R (1984) Mercury pollution in marine sediments near a chloralkali plant: distribution and availability of the metal. Sci Total Environ 39:15-26

13. Gonzalez H (1991) Mercury pollution caused by a chlor-alkali plant. Water Air Soil Pollut 56:83-93

14. Crockett AB, Kinnison RR (1979) Mercury residues in soil around a large coal-fired power plant. Environ Sci Techno 13:465-476

15. Jamali MK, Kazi TG, Arain MB, Afridi HI, Jalbani N, Memon AR (2007) Heavy metals from soil and domestic sewage sludge and their transfer to sorghum plants. Environ Chem Lett 5:209-218

16. Pacyna JM, Keeler GJ (1995) Sources of mercury in the Arctic. Water Air Soil Pollut 80:621-632

17. Zhou Y, Zhang M, Wang D, Wang L (2005) Study on a novel semidry flue gas desulfurization with multi-fluid alkaline spray generator. Ind Eng Chem Res 44:8830-8836

18. Tabak H, Lens P, Hullebusch E, Dejonghe W (2005) Developments in bioremediation of soils and sediments polluted with metals and radionuclides- 1 . Microbial processes and mechanisms affecting bioremediation of metal contamination and influencing metal toxicity and transport. Rev Environ Sci Biotechnol 4:115-156

19. Gavrilescu M (2004) Removal of heavy metals from the environment by biosorption. Eng Life Sci 4:219-232

20. Lee YF, Nan FH, Chen MJ, Wu HY, Ho CW, Chen YY, Huang CC (2012) Detection and removal of mercury and lead ions by using gold nanoparticle-based gel membrane. Anal Methods 4(6):1709

21. Lo S-I, Chen P-C, Huang C-C, Chang H-T (2012) Gold nanoparticle-aluminum oxide adsorbent for efficient removal of mercury species from natural waters. Environ Sci Technol 46:2724-2730

22. Yan N-Q, Qu Z, Chi Y, Qiao S-H, Dod RL, Chang S-G et al (2009) Enhanced elemental mercury removal from coal-fired flue gas by sulfur chlorine compounds. Environ Sci Technol 43:5410-5415

23. Liu Y, Xie S, Li Y, Liu Y (2007) Novel mercury control technology for solid waste incineration: sodium tetrasulfide (STS) as mercury capturing agent. Environ Sci Technol 41:1735-1739

24. Ku Y, Wu M-H, Shen Y-S (2002) Mercury removal from aqueous solutions by zinc cementation. Waste Manag 22(7):721-726

25. Vegliò F, Beolchini F (1997) Removal of metals by biosorption: a review. Hydrometallurgy 44:301-316

26. Ojea-Jimenez I, Lopez X, Arbiol J, Puntes V (2012) Citratecoated gold nanoparticles as smart scavengers for mercury(II) removal from polluted waters. ACS Nano 6:2253-2260

27. Wang C, Tao S, Wei W, Meng C, Liu F, Han M (2010) Multifunctional mesoporous material for detection, adsorption and removal of $\mathrm{Hg} 2+$ in aqueous solution. $\mathrm{J}$ Mater Chem 20:4635-4641

28. Wang F-H, Jiang W, Fang Y, Cheng C-W (2015) Preparation of $\mathrm{Fe} 3 \mathrm{O} 4$ magnetic porous microspheres (MPMs) and their application in treating mercury-containing wastewater from the polyvinyl chloride industry by calcium carbide method. Chem Eng $\mathbf{J}$ 259:827-836

29. Robles I, Bustos E, Lakatos J (2015) Comparison of the sorption behavior of mercury (II) on inorganic, organic and biomass substrates in the presence of different counter-ions. Sustain Environ Res 25:255-260

30. Dutta S, Bhattacharyya A, De P, Ray P, Basu S (2009) Removal of mercury from its aqueous solution using charcoal-immobilized papain (CIP). J Hazard Mater 172:888-896

31. Rmalli SWA, Dahmani AA, Abuein MM, Gleza AA (2008) Biosorption of mercury from aqueous solutions by powdered leaves of castor tree (Ricinus communis L.). J Hazard Mater 152:955-959

32. Velicu M, Fu H, Suri RPS, Woods K (2007) Use of adsorption process to remove organic mercury thimerosal from industrial process wastewater. J Hazard Mater 148(3):599-605

33. Krishnan KA, Anirudhan TS (2002) Removal of mercury(II) from aqueous solutions and chlor alkali industry effluent by steam activated and sulphurised activated carbons prepared from bagasse pith: kinetics and equilibrium studies. J Hazard Mater B92:161-183

34. Nadereh Rahbar AJ, Javad Khodayar M (2014) Mercury removal from aqueous solutions with chitosan-coated magnetite nanoparticles optimized using box behnken design. Jundishapur J Nat Pharmaceutical Products 9(2):e15913

35. Parham H, Zargar B, Shiralipour R (2012) Fast and efficient removal of mercury from water samples using magnetic iron oxide nanoparticles modified with 2-mercaptobenzothiazole. J Hazard Mater 205-206:94-100

36. Peng ZG, Hidajat K, Uddin MS (2003) Extraction of 2-hydroxyphenol by surfactant coated nanosized magnetic particles. J Chem Eng 20:896-901 
37. Langmuir I (1918) The adsorption of gasses on plane surfaces of glass, mica and platinum. J Am Chem Soc 40:1362-1403

38. Yang RT (2003) Adsorbent: fundamental and applications. Wiley, Hoboken, New Jersey

39. Voudrias E, Fytianos F, Bozani E (2002) Sorption description isotherms of dyes from aqueous solutions and waste waters with different sorbent materials Global Nest. Int J 4:75-83

40. Mohan S, Karthikeyan J (1997) Removal of lignin and tannin color from aqueous solution by adsorption on to activated carbon. Environ Pollut 97:183-187

41. Tempkin MI, Pyzhev V (1940) Kinetics of ammonia synthesis on promoted iron catalyst. Acta Phys Chim USSR 12:327-356

42. Yam VWW, Au VKM, Leung SYL (2015) Light-emitting selfassembled materials based on $\mathrm{d} 8$ and $\mathrm{d} 10$ transition metal complexes. Chem Rev 115:7589-7728
43. Shafeeq A, Muhammad A, Sarfraz W, Toqeer A, Rashid S, Rafiq MK (2012) Mercury removal techniques for industrial waste water. Int Sci Index 6:1180-1183

44. Ho TC, Yang P, Kuo TH, Hopper JR (1998) Characteristics of mercury desorption from sorbents at elevated temperatures. Waste Manag 18:445-452

45. Rezaee A, Derayat J, Mortazavi SB, Yamini Y, Jafarzadeh MT (2005) Removal of Mercury from chlor-alkali Industry Wastewater using Acetobacter xylinum Cellulose. Am J Environ Sci $1: 102-105$ 